\title{
Surface Available to Nitrogen in Hydrated Portland Cements
}

\author{
By Raymond L. Blaine and Harold J. Valis
}

\begin{abstract}
Measurements were made of the adsorption of nitrogen, oxygen, and argon at or near the boiling point of the adsorbate on samples of hydrated portland cement. Surface-area values calculated on the basis of the Brunauer-Emmett-Teller theory indicated an increase in surface available to nitrogen with age of test specimens when a high water-cement ratio was used in preparing the paste but not when a low water-cement ratio was used. Temperature of storage and type of moist storage made little difference in the apparent surface available to nitrogen. Surface values calculated from the $\mathrm{N}_{2}, \mathrm{O}_{2}{ }^{*}$, and $\mathbf{A}$ isotherms were much smaller than those previously reported, which were calculated from the adsorption of water vapor.
\end{abstract}

\section{Introduction}

The low-temperature adsorption test, in which nitrogen or another inert gas is adsorbed at or near the boiling point of the gas, has been used for a number of years as a measure of the surface areas of particulate materials [1]. ${ }^{1} \quad$ It is also used to measure the internal surface of porous materials, that is, the surface of pores large enough for the gas molecule to enter [2]. Hydrated portland cement paste is a porous solid, as evidenced by water permeability and water absorption measurements [3]. However, different cements and different quantities of mixing water used in making the neat paste, as well as different curing conditions, result in different pore structures in the hydrated specimens [4]. Furthermore, there is evidence that changes take place in the pore structure and crystal form as a cement continues to hydrate [5].

Powers and Brownyard [6] made studies of the internal surface areas of hydrated portland cement pastes by using water vapor as the adsorbate. In the present study it seemed desirable to use a gas that would be less reactive with the cement constituents, in order to measure the internal

${ }^{1}$ Figures in brackets indicate the literature references at the end of this paper.

Surface of Hydrated Portland Cement surface areas of the partially hydrated portland cement pastes.

The purpose of this study was to determine some of the variables of the nitrogen adsorption method, the applicability of the low-temperature adsorption method to the study of hydrated cements, and the precision of the test method. It was also desired to determine the effect of various factors such as storage, age, and watercement ratio of hydrated paste on the surface areas available to nitrogen.

\section{Scope}

In the low-temperature adsorption test it is necessary to evacuate the sample in order to clear the surfaces of adsorbed or absorbed molecules. Ordinarily this is done at a temperature of $200^{\circ}$ to $400^{\circ} \mathrm{C}$. However, compounds having water of crystallization, such as are found in hydrated portland cement, may lose this water at such temperatures. It was necessary, therefore, to evacuate the samples at various temperatures in order to determine the effect of the temperature of evacuation on the calculated surface values. Thermal analyses were also made of the granulated pastes evacuated at different temperatures. In the preliminary tests the effect of size upon 
apparent surface area was investigated to determine whether the $1 / 2$ by 2 -in. specimens could be tested whole or had to be broken up into granules, and what size of granules would be required.

It was not practicable to make duplicate determinations in all cases. However, determinations were made on five specimens prepared on different days, in which an attempt was made to keep all variables constant in order to obtain data on the reproducibility of the surface values obtained.

Although the surface area calculations are based on the portion of the adsorption curve between partial pressures of 0.05 and 0.30 , the nature of the entire adsorption and desorption curve is of importance in interpreting some of the results. The complete adsorption isotherm was determined for only one sample in this series. This isotherm was similar to others previously determined for cement pastes in this laboratory; hence most isotherms were determined only to a partial pressure of 0.5 . Most of the determinations were made by using nitrogen as the adsorbate; a few tests were made using argon and oxygen.

Measurements were made to determine the effect of the water-cement ratio used in preparing the neat paste, the type of storage (moist air or water), and the temperature and time of storage on the surface area available to nitrogen. Most of the tests were made by using one cement; a few were made with other cements.

\section{Materials and Methods of Test}

The portland cement used for the majority of the tests in this investigation met the requirements for Type I cement of Federal Specification SS-C-191b. A few surface area determinations were also made on specimens of the high-early strength and type II cements used in the ASTM, C-1 cooperative investigation (1948).

Cement pastes were made by using watercement ratios of $0.25,0.40$, and 0.55 by weight. The cement and water were mixed in a beaker for 5 min by means of a spatula. The paste was then poured into paraffin-lined brass molds, $1 / 2$ in. in diameter and 2 in. deep. The brass mold was sealed to a brass plate with rosin-paraffin mixture previous to filling with the paste. The mold with paste was stored in moist air for the first $24 \mathrm{hrs}$. For the $21^{\circ} \mathrm{C}$. storage, the 90 -percent relative humidity moist cabinet ordinarily used in cement testing was used. For the $5^{\circ} \mathrm{C}$. storage, the mold containing the specimens was stored in a tight jar containing a small quantity of distilled water, which was immersed in a constant-temperature bath maintained at $5.0^{\circ} \pm 0.5^{\circ} \mathrm{C}$.

A similar procedure was used for the $38^{\circ} \mathrm{C}$ storage, except that the jar with mold was placed in an oven maintained at $38^{\circ} \pm 1^{\circ} \mathrm{C}$. After 24 hrs, the specimens were removed from the molds, stripped of any adhering paraffin and stored either at $5^{\circ}, 21^{\circ}$, or $38^{\circ} \mathrm{C}$ over distilled water in closed containers or in water in the regular cementspecimen storage tank maintained at $21^{\circ} \pm 1^{\circ} \mathrm{C}$.

Twenty-four hours after casting, some specimens were broken to granules in a mortar. These granules were sieved, the 10-20 mesh material being saved for some specimens. For others, the 20-50 mesh or the 50-100 mesh materials were saved for test. Additional specimens were broken into granules and sieved after specified periods of storage immediately before test.

Specimens were sealed into sample holders at $1,3,7,28$, and 84 days after casting. The

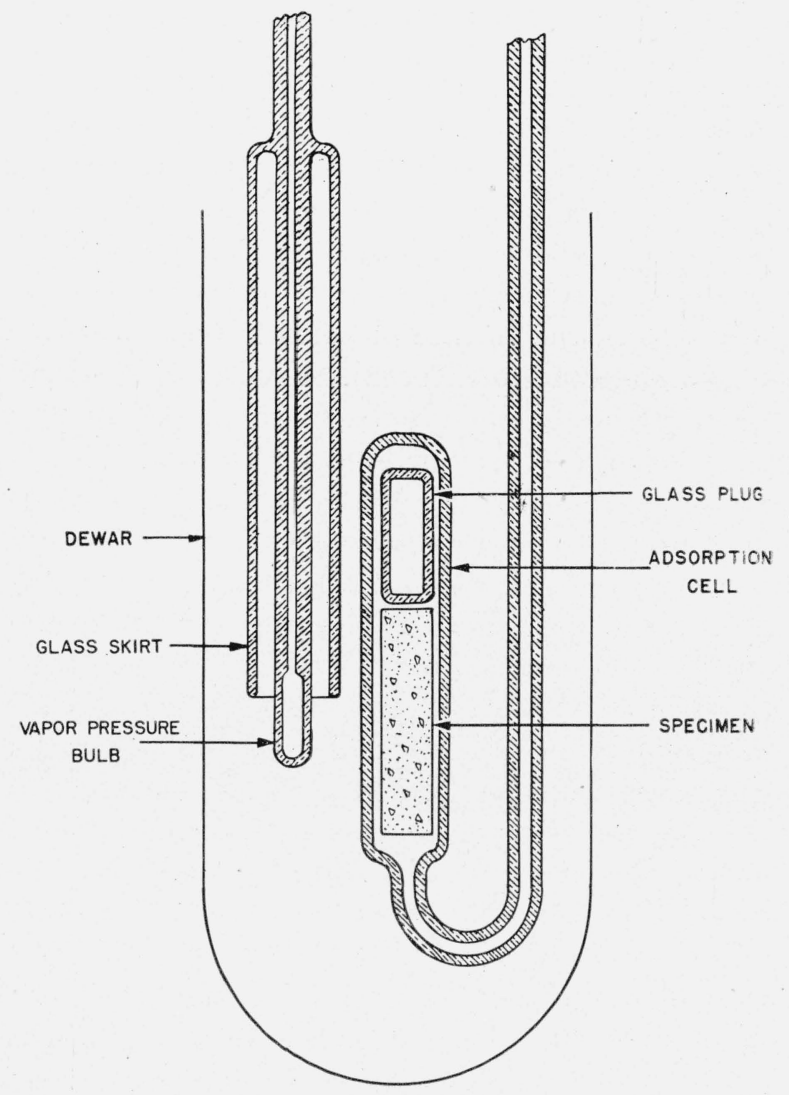

Figure 1. Specimen holder and vapor-pressure bulb. 
samples were immediately evacuated, and the adsorption tests were made the following day. The coating formed on water-stored specimens was scraped off before test.

A piece of closed-off glass tubing wàs placed between the specimen and the top seal to prevent drying of the specimen in the sealing operation (see fig. 1). The sample was then evacuated to less than $1 \mathrm{~mm} \mathrm{Hg}$ at room temperature for approximately 6 hrs by means of a mechanical vacuum pump. The specimen holder was then attached to the adsorption apparatus and evacuated by means of a mercury diffusion pump for a period of approximately $16 \mathrm{hr}$. The vacuum attained in the system was of the order of $1 \times 10^{-6}$ mm of mercury as measured by means of a McLeod gage. An oven was placed around the sample container after attaching it to the apparatus for the tests in which the sample was evacuated at $100^{\circ}$ to $110^{\circ} \mathrm{C}$ or $200^{\circ}$ to $210^{\circ} \mathrm{C}$.

Specimens were weighed before sealing into the sample containers. In order to determine the loss of water, the sealed specimen holder with sample was weighed before evacuation and again immediately after the adsorption test. The original weight of the sample minus the loss during evacuation was taken as the basis for computing the surface area per gram and also for computing the loss of water in evacuation. Ordinarily the specimen tested had a dry weight of 7 to 10 $\mathrm{g}$ depending, in part at least, on the water-cement ratio used in the original paste.

The apparatus used for determining the adsorption isotherm was of the volumetric type, which has previously been described [1]. The volume of the sample bulb not occupied by the solid portion of the sample was determined by means of helium, which had been passed over activated charcoal in a liquid nitrogen bath just before admission to the adsorption apparatus. The volume of helium admitted was determined from four pressure-volume measurements. Four additional pressure-volume measurements were made with the helium to determine the volume of the sample bulb not occupied by the solid. This calibration was made with the sample bulb immersed in liquid nitrogen or oxygen, depending on the gas to be adsorbed. After the helium calibration, the sample was evacuated for $2 \mathrm{hrs}$ at room temperature.

Water-pumped tank nitrogen purified by passage over magnesium perchlorate, chabasite, copper turnings at $400^{\circ} \mathrm{C}$ and then through magnesium perchlorate immediately before admission to the apparatus was used for the adsorption measurements with most samples. The nitrogen entering the adsorption apparatus was allowed to come to room temperature, and its volume was determined after which the nitrogen was admitted to the sample bulb. After equilibrium had been attained (usually in about $20 \mathrm{~min}$ but at times longer than $1 \mathrm{hr}$ ), the volume of nitrogen not adsorbed was determined. Additional nitrogen was then added either from the burette system or from the tank, and the above process was repeated. All volumes were calculated on the basis of the volume at $0^{\circ} \mathrm{C}$ and $760 \mathrm{~mm}$ mercury pressure. Corrections were made for density of the mercury in the manometers, the changes in scales with temperature, and for the "nonideal" behavior of the gas in the dead space around the sample.

Five or more values at partial pressures between 0.05 and 0.35 on the adsorption isotherm were determined for each of the samples. Additional values were obtained up to partial pressures of 0.5 to 0.7 on most of the samples, and on one sample the adsorption curve was obtained to above 0.9 partial pressure, after which desorption values were obtained.

The vapor pressure of the adsorbate was determined from the condensed adsorbate in a vapor pressure bulb in the bath alongside the sample (see fig. 1). The glass tube leading from the bulb to the manometer was jacketed with a larger tube in order to measure the vapor pressure near the adsorption bulb rather than at the surface of the bath, which may be slightly cooler than the sample.

Oxygen gas was used as the adsorbate on one sample, using a liquid oxygen bath. Argon was used as the adsorbate on one sample using a liquid oxygen bath and on another sample using a liquid nitrogen bath.

Surface areas of all samples were evaluated by means of the BET equation [7] as follows:

$$
\frac{P}{V\left(P_{0}-P\right)}=\frac{1}{V_{m} C}+\frac{(C-1) P}{V_{m} C P_{0}},
$$

where

$$
\begin{aligned}
& P=\text { pressure of adsorbate } \\
& P_{0}=\text { vapor pressure of adsorbate at temperature } \\
& \text { of bath, }
\end{aligned}
$$


$V=$ volume of gas adsorbed (standard temperature and pressure) at pressure $P$,

$V_{m}=$ volume of gas required for monolayer,

$C=k e$ exponential $\left(E_{1}-E_{L}\right) / R T$,

$k=\mathrm{a}$ constant,

$E_{1}=$ heat of adsorption,

$E_{L}=$ heat of liquefaction,

$R=$ gas constant,

$T=$ absolute temperature.

$P / V\left(P_{0}-P\right)$ was plotted against the partial pressure $P / P_{0}$. The slope and intercept of a line drawn through the points on the graph between partial pressures of 0.05 and 0.30 were used to evaluate $V_{m}$ and $C$. The area on the surface occupied by each molecule corresponds with those calculated by Emmett [1] from the liquid or solid density, molecular weight, and Avogadro's number. The values for area occupied by each molecule as used for the surface area calculations were as follows: $\mathrm{N}_{2}, 16.2 \mathrm{sq} \mathrm{A} ; \mathrm{O}_{2}, 14.1 \mathrm{sq} \mathrm{A}$; argon at liquid-nitrogen temperature, $12.8 \mathrm{sq} \mathrm{A}$ and at liquid-oxygen temperature, $14.4 \mathrm{sq}$ A.

In order to study the pore diameters of the hydrated specimens, isotherms were calculated on the basis of the $V_{m}$ and $C$ values obtained for the particular samples [7]. Various values of $n$ were substituted in the following equation and these calculated isotherms were superimposed on the adsorption isotherm.

$$
V=\frac{V_{m} C x}{1-x} \frac{1-(n+1) x^{n}+n x^{(n+1)}}{1+(c-1) x-c x^{(n+1)}},
$$

where

$n=$ maximum number of layers that can be adsorbed on the walls of the capillary,

$x=P / P_{0}$,

$V, C$, and $V_{m}$ are the same as in the previous equation.

The values reported are the results of single determinations. In order to determine the precision of the test results, five determinations were made in which the water-cement ratio, curing conditions, age, and temperature of evacuation were nominally constant. These five determinations were made on different days over a period of about 3 months during the period when most of the other tests were made.

\section{Results of Tests}

\section{Effect of Temperature of Evacuation}

The effect of the temperature of evacuation on the apparent surface was determined on both the $1 / 2$ - by 2 -in. specimens and on the 10-20 mesh granules. A water-cement ratio of 0.55 was used in preparing the pastes. The granules were prepared at $24 \mathrm{hr}$, and the granules and whole specimens were stored in moist air at $21^{\circ} \mathrm{C}$ until tested at 7 days. The values of surface areas available to nitrogen, calculated on the basis of the weight of the evacuated specimens, are presented in the tabulation below. Presented also are the amounts of water removed from the specimens expressed as a percentage of the weight of the evacuated sample.

\begin{tabular}{|c|c|c|c|c|}
\hline \multicolumn{3}{|c|}{$1 / 2-$ by 2 -in. specimens } & \multicolumn{2}{|c|}{$\begin{array}{l}\text { 10-20 mesh } \\
\text { granules }\end{array}$} \\
\hline $\begin{array}{c}\text { Temperature of } \\
\text { evacuation }\end{array}$ & Surface & $\begin{array}{l}\text { Water } \\
\text { loss }\end{array}$ & Surface & $\begin{array}{l}\text { Water } \\
\text { loss }\end{array}$ \\
\hline $\begin{array}{c}{ }^{\circ} C \\
25 \ldots \\
100 \ldots \ldots \\
200 \ldots \ldots\end{array}$ & $\begin{array}{r}m^{2} / g \\
14.5 \\
\text { a } 25.9 \\
27.9\end{array}$ & $\begin{array}{c}\% \\
20.9 \\
\text { a } 30.7 \\
32.9\end{array}$ & $\begin{array}{l}m^{2} / g \\
20.3 \\
33.2 \\
35.7\end{array}$ & $\begin{array}{l}\% \\
25.4 \\
30.0 \\
33.8\end{array}$ \\
\hline
\end{tabular}

a A verage of 5 determinations.

It is apparent from this table that the higher the temperature of evacuation the greater is the amount of surface available to nitrogen. The amount of water removed from the specimens also increased with increased temperature of evacuation. Inasmuch as the surface area values were calculated on the basis of the weight of the specimens after evacuation, these values are not on a comparable basis as far as the actual cement content of the specimens is concerned. A better basis of comparison would probably have been the actual cement content or the ignited weight of the samples tested. This was not apparent at the time of test, but is suggested for further studies. Although the values determined after evacuation at $200^{\circ} \mathrm{C}$ were greater by a significant amount than the values determined after evacuation at $100^{\circ} \mathrm{C}$, the difference was small as compared to the difference between the $25^{\circ}$ and $100^{\circ} \mathrm{C}$ evacuations. Because of this, the remaining samples were evacuated at $100^{\circ}$ to $110^{\circ} \mathrm{C}$ after the pre- 
liminary evacuation at room temperature to take out most of the water. Evacuation at $100^{\circ} \mathrm{C}$ is, however, quite arbitrary, and different surface area values are obtained at different temperatures of evacuation.

Thermal analyses made of granulated samples evacuated at approximately $25^{\circ}, 100^{\circ}$, and $200^{\circ} \mathrm{C}$ indicated a loss of water of crystallization with samples evacuated at both $100^{\circ}$ and $200^{\circ} \mathrm{C}$. Nearly as much loss of water occurred during the $100^{\circ} \mathrm{C}$ evacuation as during the $200^{\circ} \mathrm{C}$ evacuation.

\section{Effect of Size of Test Specimens}

It may be noted in the tabulation on page 260 that the 10-20 mesh granules had greater higher values for surface area than the whole specimens (solid cylinders) at each of the temperatures of evacuation. By using the same water-cement ratio and storage as in the previous tests, 20-50 and 50-100 mesh granules were prepared at 1 day and tested at 7 days to determine the effect of size of specimens. The samples were evacuated at $100^{\circ}$ to $110^{\circ} \mathrm{C}$. The values obtained for surface area available to nitrogen and the quantity of water removed in evacuation are presented in the tabulation below. Also included in this table are the results obtained with the $1 / 2$ - by 2 -in. specimens and $1 / 2-$ by 2 -in. specimens made with a $1 / 1 /$-in. core, which was removed at the time of initial set, leaving a hollow cylinder.

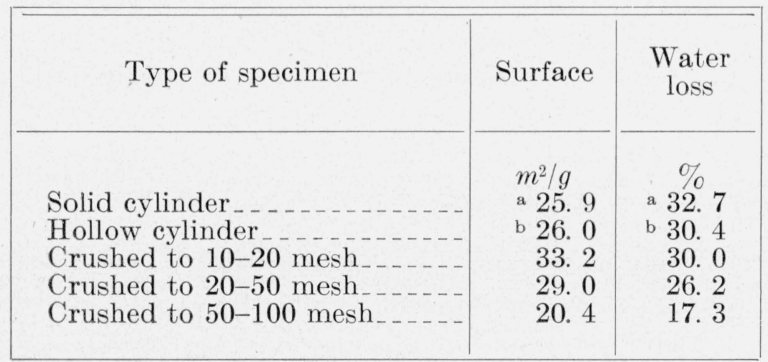

s Average of 5 determinations.

b A verage of 2 determinations.

One would expect that breaking the specimens into granules would not only make the interior surface more readily available but would also create new surface in those instances where crystals are fractured. The 10-20 and 20-50 mesh granulated materials had higher surface area values than did the whole specimens but there was an apparent decrease in surface with decrease in

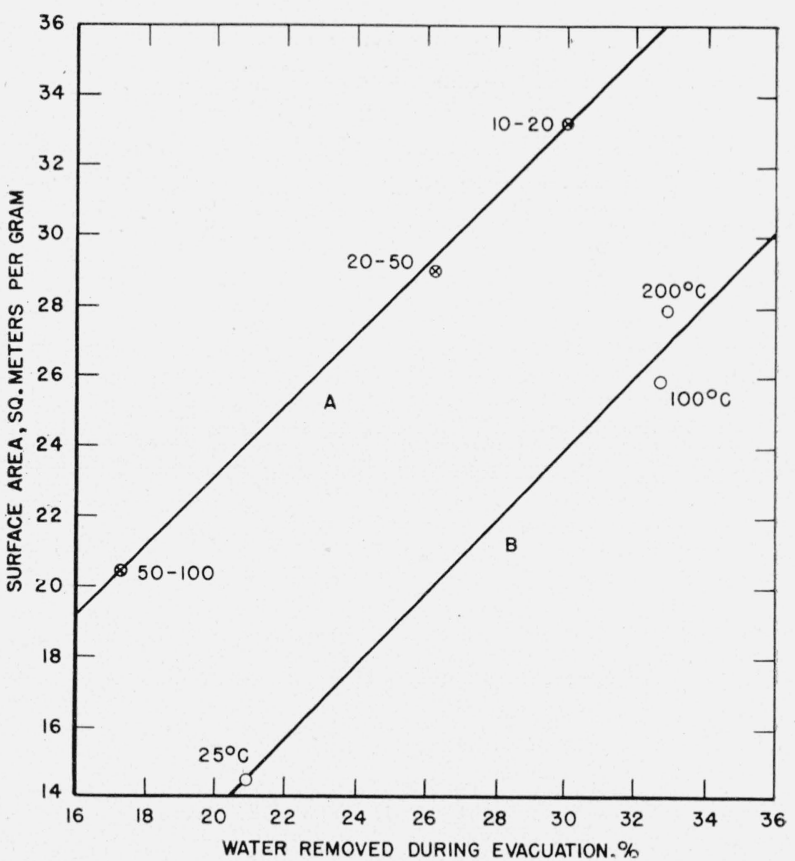

FIgURE 2. Relation of surface area to water removed during evacuation at various temperatures.

Whole specimens and granules were made by using a water-cement ratio of 0.55 and were moist-air cured for 7 days. A, Granules evacuated at $100^{\circ} \mathrm{C}$; $\mathrm{B}$, whole specimen.

size of granules. The relation of the apparent surface area to the percentage of water loss of the different size granules is presented in figure 2 . Presented also in this figure are the data from the tabulation on page 260 showing the relation of the surface area of the whole specimens, evacuated at different temperatures, to the water loss. Other tests made on granulated samples are reported under the section on autogenous healing.

There was no great difference observed in the rate of adsorption of the granulated and the whole specimens. Inasmuch as the whole specimens appeared satisfactory from the standpoint of testing procedure and breaking the specimens to granules added another variable (that of the size of the granules), the remaining tests were made on whole specimens.

\section{Reproducibility}

Five $1 / 2$ - by 2 -in. specimens were made on different days using a water-cement ratio of 0.55 and stored in moist air at $21^{\circ} \mathrm{C}$. The age of the specimens at the start of the test was 7 days in each case, and the specimens were all evacuated 
at $100^{\circ}$ to $110^{\circ} \mathrm{C}$. The surface areas determined for the specimens were as follows:

\begin{tabular}{|c|c|c|}
\hline Test specimen number & Surface & $\begin{array}{c}\text { Water } \\
\text { loss }\end{array}$ \\
\hline $\begin{array}{l}1 \\
1^{2}-\ldots-1 \\
3 \\
3 \\
4 \\
4 \\
5\end{array}$ & $\begin{array}{l}m^{2} / g \\
26.24 \\
25.51 \\
\text { 25. } 58 \\
\text { 26. } 20 \\
\text { 26. } 20\end{array}$ & $\begin{array}{l}\% \\
34.0 \\
29.6 \\
32.7 \\
32.9 \\
34.5\end{array}$ \\
\hline $\begin{array}{l}\text { Average } \\
\text { Standard deviation } \\
\text { Coefficient of variation, } \%\end{array}$ & $\begin{array}{l}25.94 \\
0.33 \\
1.3\end{array}$ & $\begin{array}{r}32.7 \\
1.9 \\
5.8\end{array}$ \\
\hline
\end{tabular}

The observed differences may be caused by variations in water-cement ratio, mixing of paste, storage of specimens, and evacuation of the specimens, as well as by errors in the testing procedure. Differences in surface-area values of less than 1 $\mathrm{m}^{2} / \mathrm{g}$ (3 times the standard deviation) cannot therefore be considered significant for single determinations. The coefficient of variation of the percentage of water loss was 5.8 percent as compared to 1.3 percent for the surface values. A part of this variation may have been caused by the amount of evaporation occurring during the sealing operation.

\section{Adsorption Isotherm}

An isotherm obtained for the adsorption of nitrogen on hydrated cement at the boiling temperature of liquid nitrogen is illustrated in figure 3 . This isotherm was obtained on a $1 / 2$ - by 2 -in. specimen, 0.55 water-cement ratio, hydrated 7 days in moist air and evacuated at $100^{\circ} \mathrm{C}$. The adsorption curve is a type 2 isotherm as classified by Brunauer-Emmett-Teller (BET) [7]. The desorption portion of the curve indicates a slight hysteresis, as is commonly found with porous adsorbents. The hysteresis loop was closed at a partial pressure of slightly above 0.4 , below which the adsorption and desorption curves coincide. Also presented in this figure are the calculated values of the number of layers that would correspond with the $V_{m}$ and $C$ values for this particu-

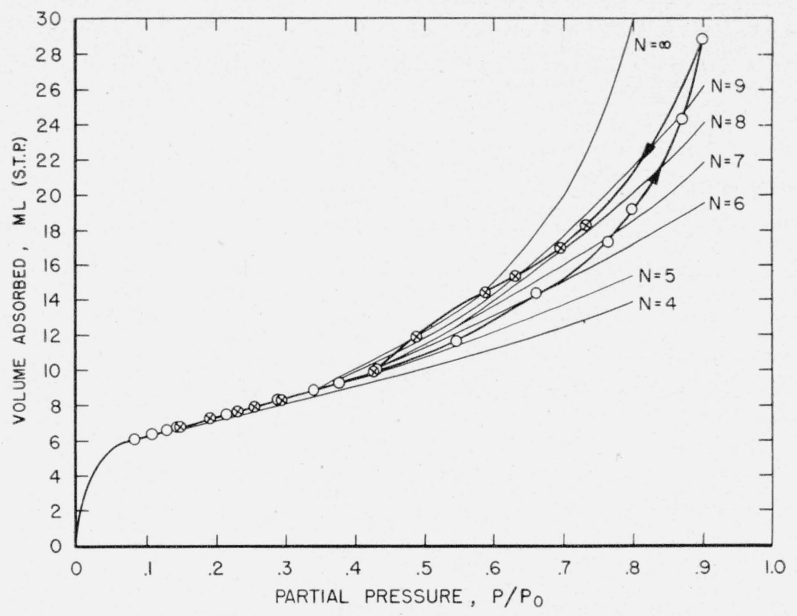

FIGURE 3. Adsorption and desorption isotherms obtained on whole specimen made with 0.55 water-cement ratio and moist-air cured for 7 days.

Included are the calculated isotherms assuming various values for the number of molecular layers $(\mathrm{N})$ that could be accommodated. $\bigcirc$, Adsorption; $\otimes$, desorption.

lar isotherm. It may be noted that the adsorption isotherm corresponds with a porous material permitting five layers of molecules up to a partial pressure of 0.5 , after which the adsorption curve crosses the lines corresponding to six, seven, eight, and nine layers. Assuming 3.15 $\mathrm{A}$ as the diameter of the nitrogen molecule, the average pore diameter is of the order of $30 \mathrm{~A}$, which corresponds very well with the 20 to $40 \mathrm{~A}$ reported by Powers and Brownyard, who used water vapor as adsorbate.

\section{Use of Different Gases as Adsorbate}

The surface area calculated from the nitrogen isotherm on the cement paste hydrated for 7 days is only about $26 \mathrm{~m}^{2} / \mathrm{g}$, whereas Powers and Brownyard reported values on the order of 100 $\mathrm{m}^{2} / \mathrm{g}$ when using water vapor as the adsorbate. Because of this difference, it seemed desirable to determine the surface area as measured by different gases. Oxygen gas was adsorbed at liquid oxygen temperature, and argon gas was adsorbed at liquid oxygen and liquid-nitrogen temperatures. Adsorption tests were made on 0.55 water-cement ratio, 7-day, $21^{\circ} \mathrm{C}$, moist-air-cured whole specimens evacuated at $100^{\circ}$ to $110^{\circ} \mathrm{C}$. The surface 
area values calculated from the adsorption isotherms are presented in the tabulation below.

\begin{tabular}{|c|c|c|c|}
\hline Adsorbate & $\begin{array}{l}\text { Temper- } \\
\text { ature }\end{array}$ & $\begin{array}{c}\text { Area/ } \\
\text { molecule }\end{array}$ & $\begin{array}{c}\text { Surface } \\
\text { area }\end{array}$ \\
\hline $\begin{array}{l}\mathrm{N}_{2} \ldots \ldots \ldots \\
\mathrm{O}_{2 \ldots \ldots} \ldots \ldots \\
\mathrm{A}_{\ldots} \ldots \ldots \ldots\end{array}$ & $\begin{array}{l}\circ C \\
-195 \\
-183 \\
-195 \\
-183\end{array}$ & $\begin{array}{c}s q A \\
16.2 \\
14.1 \\
14.4 \\
12.8\end{array}$ & $\begin{array}{l}m^{2} / g \\
25.9 \\
20.8 \\
19.4 \\
20.7\end{array}$ \\
\hline
\end{tabular}

Although the values for surface area obtained with the use of oxygen and argon are somewhat lower than those obtained with the use of nitrogen, they are of the same order. The values are, however, much lower than those obtained with water vapor.

\section{Effect of Water-Cement Ratio and Age of Test Specimens}

Specimens were made with water-cement ratios of $0.55,0.40$, and 0.25 and stored in moist air at $21^{\circ} \mathrm{C}$. The specimens were tested at $1,3,7,28$, and 84 days. All of these specimens were evacuated at $100^{\circ}$ to $110^{\circ} \mathrm{C}$. The results of these tests are presented in figure 4 . Whereas the more porous paste (highest water-cement ratio) indi-

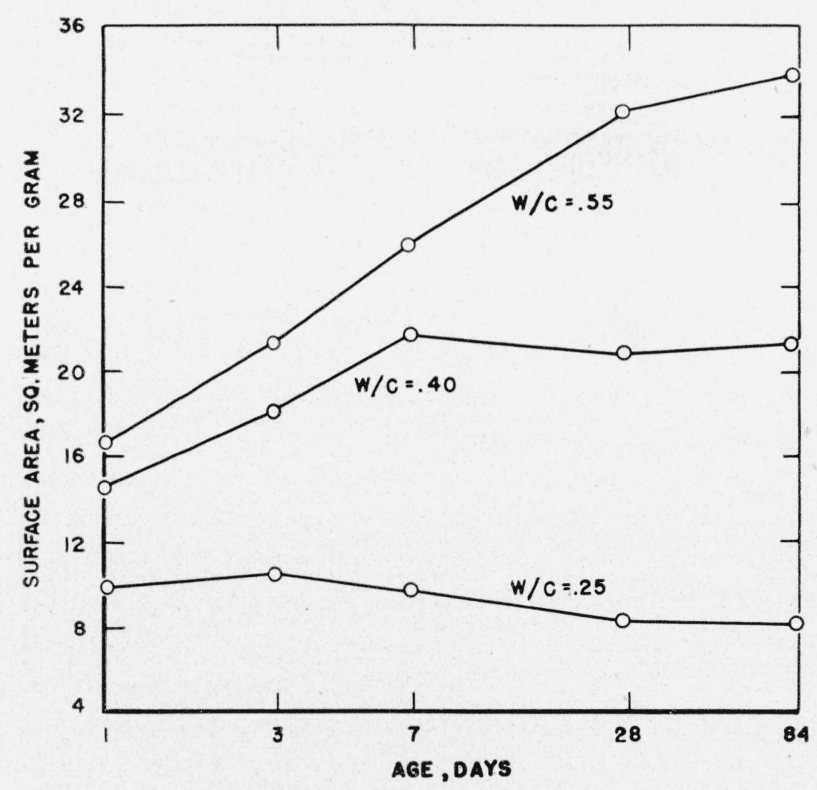

Figure 4. Surface area available to nitrogen of 1/2-by 2-in. specimens made with different water-cement ratios, cured in moist air at $21^{\circ} C$ for different periods of time and tested at various ages.

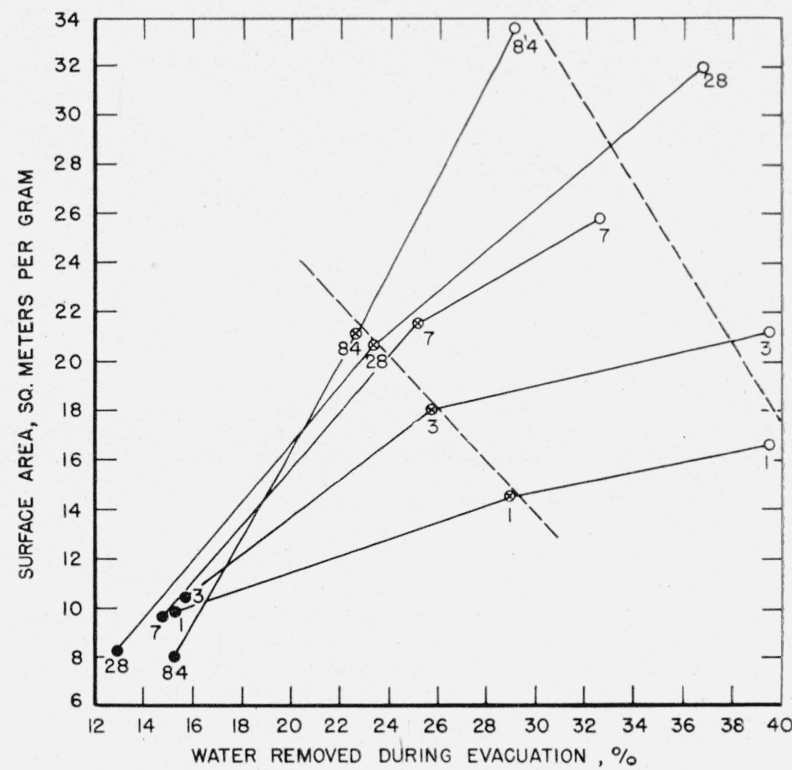

Figure 5. Surface area available to nitrogen versus percentage of water remoced in evacuation of 1/2- by 2-in. specimens made with different water-cement ratios, moist-air cured and tested at various ages.

$\bigcirc, \mathrm{w} / \mathrm{c}=0.55 ; \otimes, \mathrm{w} / \mathrm{c}=0.40 ; \bullet, \mathrm{w} / \mathrm{c}=0.25$.

cates an increase in the surface available to nitrogen with age, the paste having the lowest water-cement ratio indicated a trend toward a decrease in surface available to nitrogen with age. The paste with an intermediate water-cement ratio had an apparent increase in surface up to 7 days, after which no significant increase was obtained up to 84 days.

The relation between the surface areas of these specimens and the percentage of water lost in evacuation is presented in figure 5. The pastes made of the 0.40 and 0.55 water-cement ratios indicated a trend of higher surface areas with lower percentages of water removed, as indicated by the dashed lines. Specimens tested at the same age are connected by lines and indicate different slopes at the different ages.

\section{Effect of Temperature of Hydration and Age}

Cement pastes of 0.55 water-cement ratio were allowed to hydrate in moist air at $5^{\circ}$ and $38^{\circ} \mathrm{C}$ for comparison with the specimens stored at $21^{\circ} \mathrm{C}$. Tests were made at $1,3,7,28$, and 84 days. All specimens were evacuated at $100^{\circ}$ to $110^{\circ} \mathrm{C}$. The results of tests are presented in figure 6 . Although the specimens stored at $5^{\circ} \mathrm{C}$ were so soft that difficulty was encountered in removing them from 


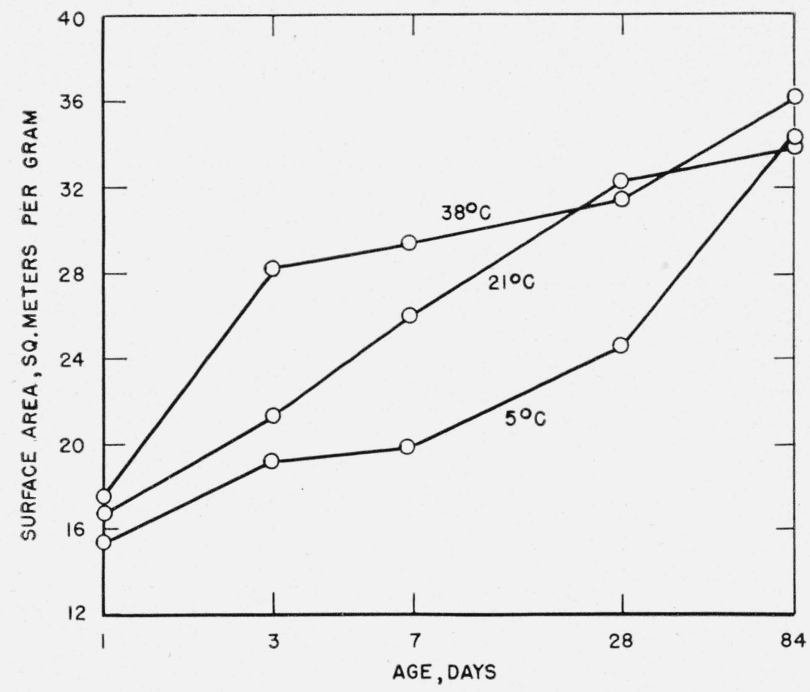

Figure 6. Effect of curing temperature and age on surface area available to nitrogen of $1 / 2-$ by 2 -in. specimens made with a water-cement ratio of 0.55 and cured in moist air.

the molds, the surface was only slightly less at 1 day than that of the specimens stored at $21^{\circ}$ or $38^{\circ} \mathrm{C}$. The specimens stored at $38^{\circ} \mathrm{C}$ indicated only a slight increase in surface after 3 days, whereas the specimens stored at $5^{\circ}$ and $21^{\circ} \mathrm{C}$ continued to increase in surface with age. The surface area vs percentage of water loss is shown in figure 11.

\section{Effect of Water and Moist Air Storage on Different Cements}

The $1 / 2$ - by 2 -in. specimens of the type I cement made with 0.55 water-cement ratio were stored in water at $21^{\circ} \mathrm{C}$ after 24 hours in the moist cabinet, for comparison with the specimens stored continuously in moist air. Specimens were also made of a type II and a type III cement and stored in water and in moist air. Coatings formed on the water-stored specimens were scraped off before they were sealed in the specimen holders. All specimens were evacuated at $100^{\circ}$ to $110^{\circ} \mathrm{C}$ after the preliminary evacuation at room temperature. A comparison of the values obtained for the different cements and storage conditions is presented in figures 7 and 8 . At 28 and 84 days the water-cured specimens of the type I cement had appreciably greater surface areas available to nitrogen than did the respective moist-air stored specimens.

The neat pastes made of the type II and the type III cement with a water-cement ratio of 0.55 and stored in moist air had greater surface area

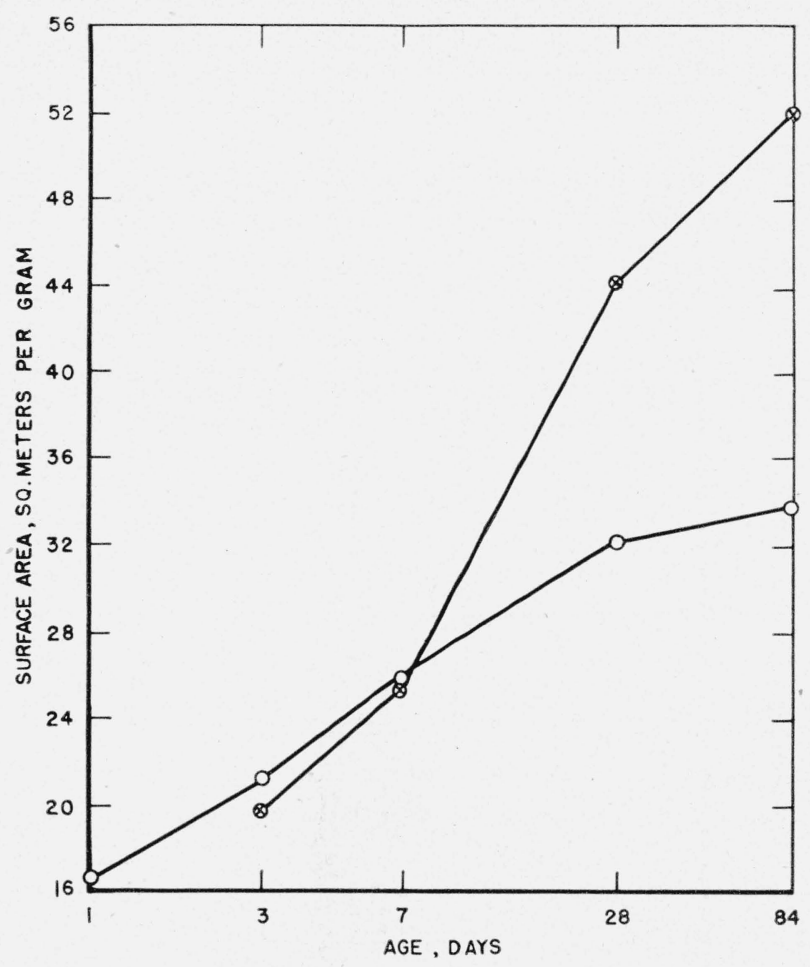

Figure 7. Surface area available to nitrogen of 1/2-by 2-in. specimens of type I cement made with 0.55 water-cement ratio and cured in moist air or in water for various ages.

$\bigcirc$, Moist-air storage; $\otimes$, water storage.

values at the respective ages than did the corresponding specimens made of the type I cement. The apparent surface of the 28-day, water-stored specimens of type II and type III cements was less than the respective moist-air stored specimens; however, the water-stored specimens of the type I cement had greater surface than did the moist-air cured specimens, at 28 days.

\section{Autogenous Healing}

In some tests made previous to the present study, normal and high-early-strength cement pastes of normal consistency (water-cement ratio approximately 0.23 ) were broken to $10-40$ mesh at 24 hours and stored in moist air at $21^{\circ} \mathrm{C}$. Surface area values were determined at various ages after evacuation at $200^{\circ} \mathrm{C}$ and are based on the weight of the evacuated granules. The results of tests are presented in figure 9. Although the results are somewhat erratic, there appears to be a definite decrease in surface available to nitrogen with age. This was believed to be caused by the autogenous healing of cracks or crevices in the 


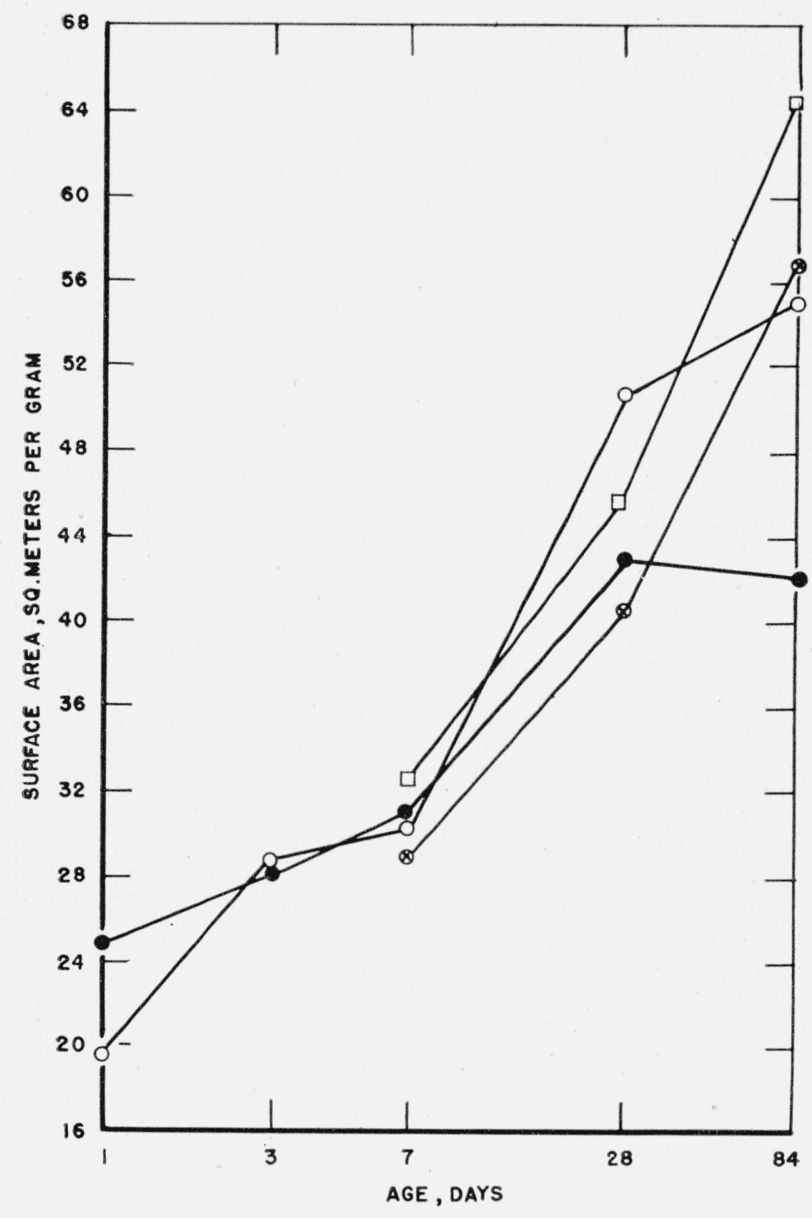

Figure 8. Surface area available to nitrogen of 1/2- by 2-in. specimens of types II and III cements made with 0.55 water-cement ratio and cured in moist air or in water for various ages.

O, Type II, moist-air storage; $\square$, type II, water storage; moist-air storage; $\otimes$, type III, water storage.

granules. However, in the present series of tests where specimens were broken at 1 day and tested at various ages and comparative specimens were granulated just previous to testing, there was no conclusive proof of autogenous healing with the higher water-cement ratio pastes. The results presented in figure 10 indicated that at two of the three ages the surface values obtained were not affected appreciably by the age at which the specimens were broken. A second. set of tests of 28-day specimens indicated the same values (within experimental error) as obtained with the first set of 28-day specimens.

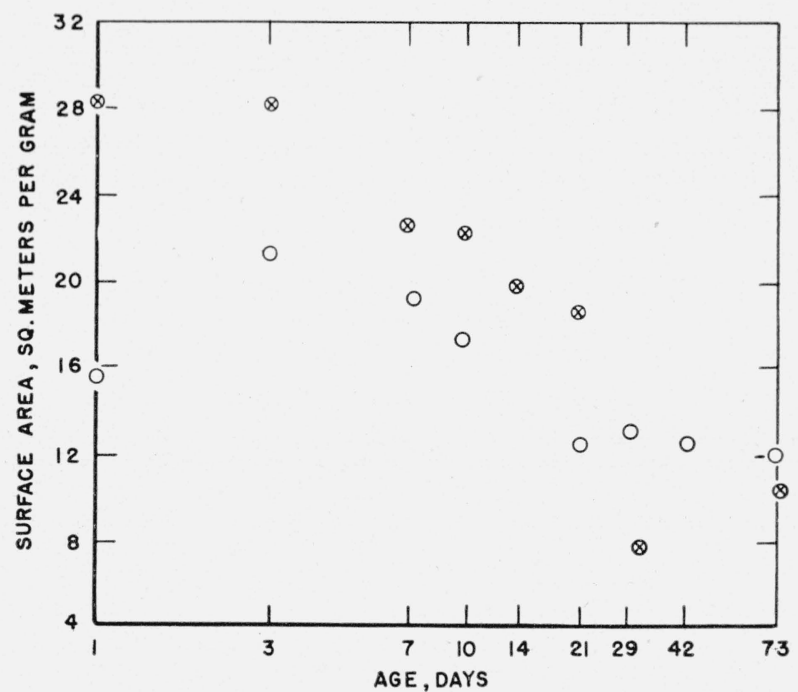

Figure 9. Effect of time of storage on surface available to nitrogen of granules of a normal portland a high-earlystrength cement paste made with 0.23 water-cement ratio.

The neat cement past was broken to granules at 1 day and stored in moist air at $21^{\circ} \mathrm{C}$ until tested. $\bigcirc$, Normal portland; $\otimes$, high-early-strength portland.

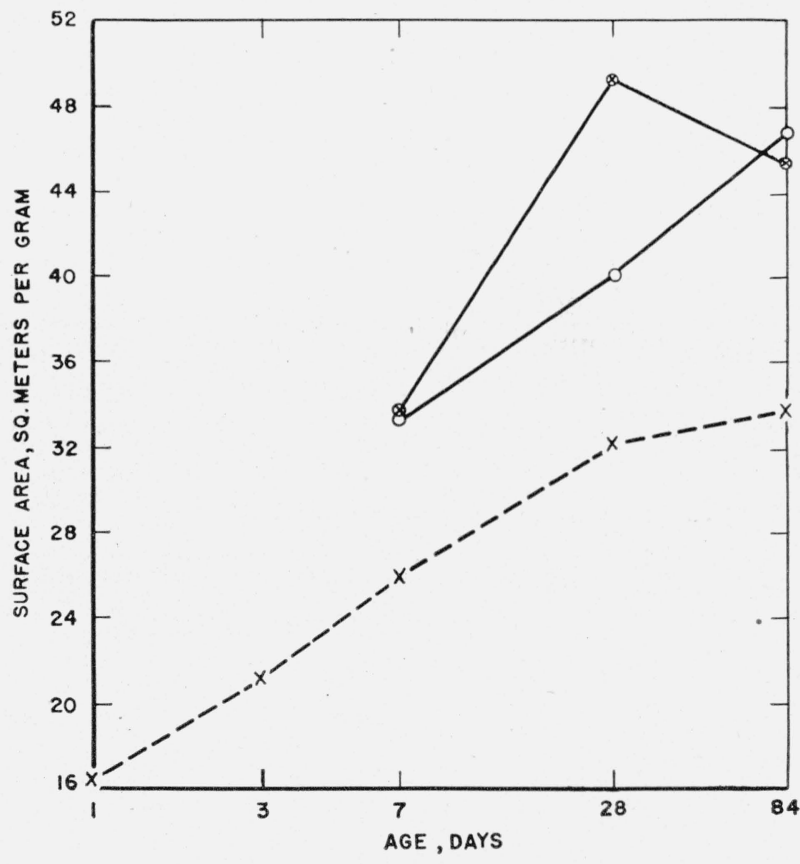

FIGURE 10. Effect of age at which the specimens were granulated on the surface available to nitrogen.

The neat pastes were made with a water-cement ratio of 0.55 , and all specimens were stored in moist air at $21^{\circ} \mathrm{C}$ until tested. $\bigcirc$, Broken at 1 day; $\otimes$, broken at age of test; $\times$, whole specimens. 


\section{Discussion}

The surface area of hydrated neat cement as measured by adsorption of nitrogen, oxygen, or argon was much lower than that reported by Powers and Brownyard [6], who used water vapor. Also, the desorption curve obtained with nitrogen did not have as large an hysteresis loop as did the curves obtained by Powers and Brownyard using water vapor. The water molecule is slightly smaller than the nitrogen molecule, hence the additional surface as measured by the water molecules may have consisted of intercrystalline spaces or pores too small for the nitrogen molecule to enter. Similar results have been obtained with montmorillonite [8], where the water molecule could apparently enter the space between the layers of mineral, whereas the larger molecules could not enter. The oxygen and argon molecules, which are smaller than the nitrogen molecule but larger than the water molecule, indicated less surface available to oxygen and argon than to nitrogen in the hydrated paste. Certain organic materials, such as paper [2] and textile fibers [9], also have greater surface areas available to water than to nitrogen. The apparent surface of paper and textile fibers available to nitrogen decreased with increased temperature of evacuation, whereas the hydrated cements showed the opposite effect.

Loss of water of crystallization is usually accompanied by an increase of surface area [10]. Certain of the compounds in hydrated portland cements may be expected to lose a portion of the water of crystallization on evacuation at $100^{\circ}$ or $200^{\circ} \mathrm{C}$, as carried out in this study. Although this evacuation was more severe than that used by Powers and Brownyard, the surface-area values were lower. There was more surface available to nitrogen also a greater loss of water when the samples were evacuated at the higher temperatures. The additional water that was removed may have been water of crystallization.

It appears then that the greater portion of the surface available to water vapor in hydrated cement pastes must consist essentially of pores smaller than $3.15 \mathrm{~A}$, the diameter of the nitrogen molecule.

Figure 11 indicates no consistent relation between the percentage of water loss on evacuation and the surface available to nitrogen of pastes

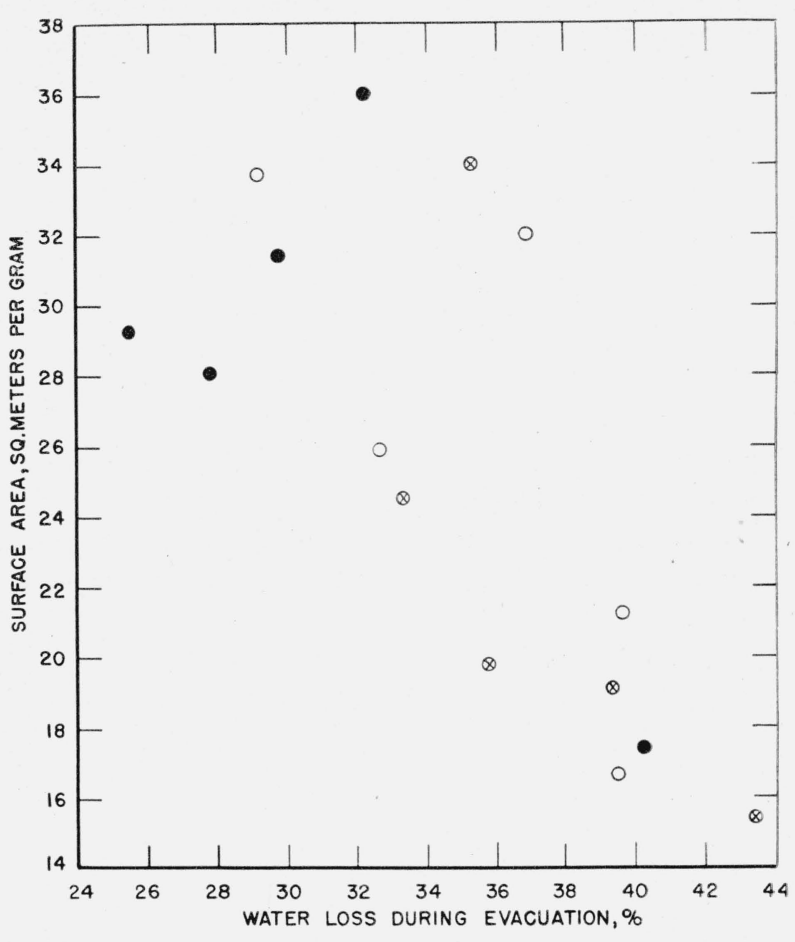

Figure 11. Surface area available to nitrogen versus percentage of water loss during evacuation of 1/2- by 2-in. specimens made of type $I$ cement with 0.55 water-cement ratio and stored in moist air at different temperatures until tested.

$\otimes, 5^{\circ} \mathrm{C}$ storage; $\bigcirc, 21^{\circ} \mathrm{C}$ storage;, $38^{\circ} \mathrm{C}$ storage.

made, with the same water-cement ratio and cured at different temperatures. However, when different water-cement ratios were used in preparing the paste, as previously indicated in figure 5, or testing different cements of the same water-cement ratio, different values were obtained.

\section{Summary}

Measurements of the internal surface of hydrated portland cement neat pastes, computed on the basis of the BET theory from the amount of nitrogen adsorbed at the temperature of liquid nitrogen, indicate that:

1. Higher surface values were obtained on specimens evacuated at the higher temperatures.

2. The hydrated cement ground to pass a No. 10 sieve and retained on a No. 20 sieve had higher surface values than did the whole specimens.

3. The surface values of granulated specimens were lower for the smaller granules. 
4. The surface values obtained by use of nitrogen at liquid nitrogen temperature were of the same order as those obtained with oxygen at liquid oxygen temperature, and argon at liquid oxygen or liquid nitrogen temperatures.

5 . The surface available to nitrogen was much less than that previously reported as available to water molecules.

6 . The surface values increased with age for specimens made with high water-cement ratio but not when made with a low water-cement ratio.

7. The surface values of specimens stored in moist air at $38^{\circ} \mathrm{C}$ were higher than those of specimens stored at $21^{\circ} \mathrm{C}$ up to 28 days.

8. The surface values of specimens stored in moist air at $5^{\circ} \mathrm{C}$ were approximately the same at 1 day as were those stored at $21^{\circ}$ or $38^{\circ} \mathrm{C}$, but increased more slowly with age than did those stored at the higher temperatures.

9. The surface values of a type I cement were higher at 28 days and 84 days after storage in water than after storage in moist air.

10. The surface values of pastes made of a type II and a type III cement were higher than those obtained with the type I cement neat paste at all ages of moist air storage.

11. The surface values of the type II and the type III cements were approximately the same when stored in water as when stored in moist air, except at 84 days when the water-stored specimens had greater surface values.

12. The pore diameter of the hydrated pastes was of the order of 30 angstroms.

\section{References}

[1] P. H. Emmett, Symposium on new methods for particle size determination in the subsieve range, Am. Soc. Testing Materials (1941).

[2] P. H. Emmett and T. De Witt, Ind., \& Eng. Chem. (Anal. Ed.) 13, 28 (1941).

[3] W. M. Dunagan, Proc. Am. Soc. Testing Materials 39, 866 (1939).

[4] L. S. Brown and R. W. Carlson, Proc. Am. Soc. Testing Materials 36, 332 (1936).

[5] R.H. Bogue, The chemistry of portland cement, p. 454 (Reinhold Publishing Corp., New York, N. Y., 1947).

[6] T. C. Powers and T. L. Brownyard, J. Am. Coner. Inst. 18, 469 (1946).

[7] S. Brunauer, The adsorption of gases and vapors, p. 153 (Princeton University Press, Princeton, N. J., 1945).

[8] S. B. Hendricks, R. A. Nelson, and L. T. Alexander, J. Am. Chem. Soc. 62, 1457 (1940).

[9] J. W. Rowen and R. L. Blaine, J. Research NBS 39, 479 (1947) RP1842.

[10] S. Brunauer and P. H. Emmett, J. Am. Chem. Soc. 59, 2682 (1937).

Washington, November 8, 1948. 